\title{
Stroke of Diabetic Subject: Experience of The Neurology Service of Cocody Teaching Hospital at Abidjan (Ivory Coast)
}

Zakaria Mamadou $^{1 *}$, Ange-Eric Assouan Kouamé ${ }^{2}$, Christian Tanoh ${ }^{1}$, Soumaila Boubacar ${ }^{3}$, Eric Bila Lamou Gueumekane ${ }^{3}$, Fataoulaye Soumana ${ }^{1}$, Ibrahim Nargoungou ${ }^{1}$, Youssoufa Maiga ${ }^{4}$ and Aka-Anghui Evelyne Diarra ${ }^{1}$

${ }^{1}$ Neurology Service of Cocody Teaching Hospital Abidjan, Ivory Coast

${ }^{2}$ Neurology Service of Bouaké Teaching Hospital, Ivory Coast

${ }^{3}$ Neurology Service of Fann Teaching Hospital Dakar, Senegal

${ }^{4}$ Neurology Service of Gabriel Touré Teaching Hospital Bamako, Mali

*Corresponding author: Zakaria Mamadou, Neurology Service of Cocody Teaching Hospital Abidjan, Ivory Coast, Tel: 971556864636; E-mail: mamadouzakaria1@hotmail.fr

Rec date: Sep 13, 2016; Acc date: Sep 24, 2016; Pub date: Sep 27, 2016

Copyright: (c) 2016 Mamadou Z, et al. This is an open-access article distributed under the terms of the Creative Commons Attribution License, which permits unrestricted use, distribution, and reproduction in any medium, provided the original author and source are credited.

\begin{abstract}
Introduction: Diabetes influences the clinical and evaluative profile of stroke. Age of up come type, the severances are as well the parameters which intervenes in the evolution.

Objectives: It describes the epidemiologic profile, clinical scannographic and evaluative of hospitalized patients for cerebro-vascular accident associated to diabetes.

Methodology: It was about a retrospective and descriptive study on 2 years, realized in the general service of Neurology and at Neurovascular unit of Cocody Teaching Hospital. All patients hospitalized for stroke, diabetes know or discovered during hospitalization was included. We have studied the epidemiologic data, clinic, scannographic and the evolution in the process of hospitalization. The TOAST classification was used for the etiologic classification of ischemic stroke.

Results: 79 cases of stroke associated to diabetes were diagnose on 596 patients hospitalized for stroke, the hospitalized prevalence is $13.25 \%$. The sex ratio was from 0.79 with an average age of 64.6 years. The diabetes type II predominated with $97.5 \%$ of cases. $79.2 \%$ of patients know they were diabetic but these ones, $61.9 \%$ were unobservant to their anti-diabetic treatment. High blood pressure was associated to diabetes in $87.3 \%$ of cases. The percentage of recidivist stroke was from $27.8 \%$. The clinical examination found a hemi corporal motor deficit in $91.6 \%$ of cases, a vigilance disorder found in $31.6 \%$ of cases and a motor aphasia in $26 \%$ of cases. Ischemic vascular cerebral accidents were predominating in $85 \%$ in cases against $21.5 \%$ of hemorrhagic stroke cases. The arteriolosclerosis was retained as etiologic of ischemic stroke in $56.5 \%$ of patients and High blood pressure in $100 \%$ of cases of Hemorrhagic stroke. We note a significant statistically correlation between the increase of $\mathrm{HbA} 1 \mathrm{C}$ rate and the intra-hospital mortality.
\end{abstract}

Conclusion: Stroke from diabetic is frequent, severe and highly dominated by lacunar infarcts in our context.

Keywords: Stroke-diabetes; Sub Saharan Africa; Ivory Coast

\section{Introduction}

Stroke represents the first cause of handicap and the third cause of deaths throughout the world. Diabetes is one of the principal factors of risk of stroke. Diabetic patients have a risk from 1.5 to 3 times more elevated stroke and in particular cerebral infarcts, than none diabetic. This excess risk is particularly marked in young subject and in women [1].

The prevalence of diabetes in patient victims of a cerebral vascular accident is evaluated to $10-20 \%$ and each elevation from $1 \%$ of $\mathrm{HbAlC}$ increase the risk of fatal stroke from $37 \%$. More to that $80 \%$ of the mortality within the diabetic population is linked to a cardiovascular disease of which stroke [2].
In the Neurology service of Cocody Teaching hospital at Abidjan, Diabetes constitutes the 5th factor of risk of stroke (18\%) after high blood pressure, alcoholism, smoking and past history of stroke [3].

In sub-Saharan Africa, little data are brought back in the association between diabetes and stroke. No data is available on the subject in Ivory Coast where the initiative of this work to finally describe the epidemiologic data, clinic, scannographic and evaluative of diabetic patients victims of stroke at the neurology service of Cocody Teaching Hospital at Abidjan.

\section{Methodology}

It concerns a retrospective study and descriptive realized in two years (1st August 2013 to 31 July 2015) at the Neurology service of Cocody Teaching Hospital and at the Neurovascular Unit of the same Service. The Neurology service has a capacity of 32 beds and the Neurovascular Unit had 8 beds. 
We have included all diabetic patients (Type I or II) or no before hospitalization, admitted for a confirmed stroke at the CT scan. The following parameters were studied: sociodemographic data, clinical and scannographic data.

The etiologies of ischemic stroke (according to the criteria of classification TOAST) and the etiologies of stroke. The correlation between the average stay of days on hospitalization and the up come of decubitus complications. The correlation between the glycemic control and the intrahospital mortality.

These data made object of a descriptive statistical analysis and analytic. For this last, we have used the $\mathrm{chi}^{2}$ test with a level of significant risk of first type fixed at $5 \%$.

Lots of patient's medical records were not in line with our inclusion criteria due to the fact that it was a retrospective work for we had wanted to treat only medical records documented by complementary examinations.

\section{Results}

\section{Socio-demographic characteristics}

During the period of study, 596 patients were hospitalized for stroke between which 79 where diabetic, a hospital prevalence of $13.25 \%$. The average age was from 64.6 years. The patients from 51 to 80 years represented $87.4 \%$ of cases (Figure 1) the female sex predominated with a sex ratio of 0.79 .

\section{Clinical characteristics}

Close to $80 \%$ of patients knew themselves to be diabetic they were all under anti-diabetic treatment but $61.9 \%$ were none observant to their antidiabetic treatment. The diabetes of type II predominated with $97.5 \%$ of cases.

High blood pressure was the principal risk factor associated to diabetes in $87.3 \%$ of cases. A recidivist of stroke was found in $27.8 \%$ of cases and between these ones $72.7 \%$ were hypertensive.

The clinical examination found a hemi corporal motor deficit in $91.1 \%$ of cases (hemiparesis in $82 \%$ of cases and hemiplegia in only $18 \%$ of cases) a vigilance disorder in $31.6 \%$ of cases, a language disorder in $45.7 \%$ constituted from a Broca-aphasia (26.6\%) and of a dysarthria in $19.1 \%$.

\section{Tomo-densitometory and etiologic characteristics}

Ischemic vascular cerebral accidents represented $78.5 \%$ of cases and the intra parenchymatous hemorrhages in $21.5 \%$ of cases. The topography of ischemic stroke interested the deeply sylvian artery territory in $40.3 \%$ of cases, of superficial sylvian artery territory in $22.6 \%$ of cases, the anterior cerebral artery in $9.7 \%$ of cases, the posterior cerebral artery in $1.6 \%$ of cases and the multiple infarcts in $24.2 \%$ of cases. The topography of parenchymatous hemorrhages concerned the basal ganglia in $58.8 \%$ and the posterior fossa (cerebellum and brain stem) in close to $12 \%$. In $29.4 \%$ of cases, it is all about deep hemorrhage (basal ganglia) with ventricular flow and mass effect.

The infarcts of large size (diameter of infarcts $>15 \mathrm{~mm}$ ) was observed in $43.5 \%$ of cases.
Arteriolosclerosis was the most frequent etiologies of ischemic stroke according to the TOAST classification (Figure 2 and Table 1). The Small arteries diseases linked to high blood pressure were retained as etiology of hemorrhagic vascular cerebral accidents of the totality of cases.

\section{Evaluative data}

We have noted a significative correlation between the elevation of the $\mathrm{HbAlC}$ and the intra hospital mortality $(\mathrm{p}<0.02)$. For a rate of HbA1C situated between 9 and $10 \%$, the percentage of mortality was from $35.7 \%$ whereas for a superior rate at $15 \%$, the mortality was increasing at $55 \%$ (Figure 3 ). The global rate of mortality was $26.6 \%$.

The average stay of day while on hospitalization was correlated to the up come of decubitus complication (independently from the rate of the HbAlC with a difference statistically significant $(\mathrm{p}<0.005)$. The global rate of decubitus complication was from $41.7 \%$.

\section{Discussion}

Type II Diabetes is a current pathology, which touches $3 \%$ to $5 \%$ of persons living in abroad countries and constitutes a risk factor well known from cerebral infarcts $[4,5]$.

In Africa, diabetes touches about 14 million in habitants (Averagely 4.8\%). In 2030 about 23.9 million inhabitants will suffer from diabetes in sub-Saharan Africa [6]. The prevalence of this pathology is from $5.7 \%$ in Ivory Coast [7].

Stroke and cardiovascular diseases represent almost $70 \%$ of mortality causes in diabetic patients $[8,9]$.

Our prevalence from $13.25 \%$ concords with certain data describes in the literature, which situated it in an interval from $9.5 \%$ to $20 \%[10,11]$. Whereas it is equally inferior to other studies which note prevalence from $16 \%$ to $24 \%$ [12]. This can be explained by the diversity of methodologies but also by the hospital character of our work.

According to the literature, our sample had a female predominance. In effect diabetic of feminine sex is exposed to a multiple stroke risk by 3 to 6.5 as compared to no diabetic [13-15]. The High blood pressure was associated to diabetes in $3 / 4$ of our patients. This association exposes patients to an acute risk of an up come of stroke. The UK prospective Diabetes Study (UKPDS) realized in hypertensive diabetic shows that a reduction in average of $10 \mathrm{~mm}$ hg of systolic artery pressure considerably reduces the risk of $44 \%$ of stroke.

Stroke of a diabetic is dominated by a less incidence of intra parenchymatous hemorrhages. Lobar hematoma was not identified in this work, that which was found in other studies. Hemorrhagic stroke are six times less frequent in diabetic patients than in none diabetic patients [16].

In our work ischemic stroke represent close to $4 / 5$ of ours sample and amongst these ones the lacunar infarcts represented $46.5 \%$. Within this while many studies have described an association between diabetes and the up come of lacunar infarcts [17-20]. Is it because majority of our patients are hypertensive? These lacunar infarcts are in effect the direct consequences of chronic complications of high blood pressure on cerebral perforates artery by lipohyalinosis and arteriolosclerosis. Diabetes is also well known as etiology of illnesses of small arteries and will mostly be probably a risk factor for lacunar infarcts [20,21]. These studies bring that Tobacco, embolic 
Citation: Mamadou Z, Kouamé AA, Tanoh C, Boubacar S, Gueumekane EBL, et al. (2016) Stroke of Diabetic Subject: Experience of The Neurology Service of Cocody Teaching Hospital at Abidjan (Ivory Coast). J Neurol Disord 4: 304. doi:10.4172/2329-6895.1000304

Page 3 of 4

cardiopathies and hyperhomocysteinemia are also lead to lacunar infarcts.

This work permitted us to do a correlation statistically significative between the elevation of the HBA1C and the incidence of the intra hospital mortality.

The mortality was $100 \%$ in the patients group having a rate of $\mathrm{Hb} 1 \mathrm{AC}$ between 13 and 14.9 while it was at $55 \%$ in the group having a rate superior to $15 \%$. This mortability variation can be simple explained by the numbers of patients included in the first group which was of one patient (dead patient) whereas in the second group it was a patient of which five dead.

This correlation was equally shown in the UKPDS Study, who notes which elevations of $\mathrm{HbA1C}$ from $1 \%$ were associated to a majority of the lethality by stroke from $37 \%$ [22]. In effect there exist a strong link between the carbohydrate metabolism disorder and the cardiovascular mortality of which stroke [1]. This acute phase especially in patients unstable in the glycemic status (with glycemic numbers).

These poor mechanisms are a less good recanalization of occluded artery via a pro-coagulation action and a reduction of a fibrinolysis, a reduction of the reperfusion of ischemic tissue and a more large height of the necrosis. This hyperglycemia will give an accent of lesions linked to the reperfusion, explaining the largest frequencies of hemorrhagic transformation during fibrinolysis treatment [22,23].

The more the duration of stay is prolonged, the more patients are exposed to do decubitus complications and this could be explained by prolonged bed lying of patients, insufficiency of health personnel in order to do nursing well (one nurse for 32 beds. This is why the parents of the patients are educated to do nursing and to give food to patients) but also nosocomial infections.

\section{Conclusion}

Diabetes is a major risk factor of stroke. Associated to the high blood pressure it exposes to an acute incidence of cardiovascular diseases of which stroke. Stroke of diabetic is frequent and serious dominated by ischemic stroke. It is equally a gravity factor of stroke in terms of mortality, the sequel and prolonged stays of intra hospitalized days.

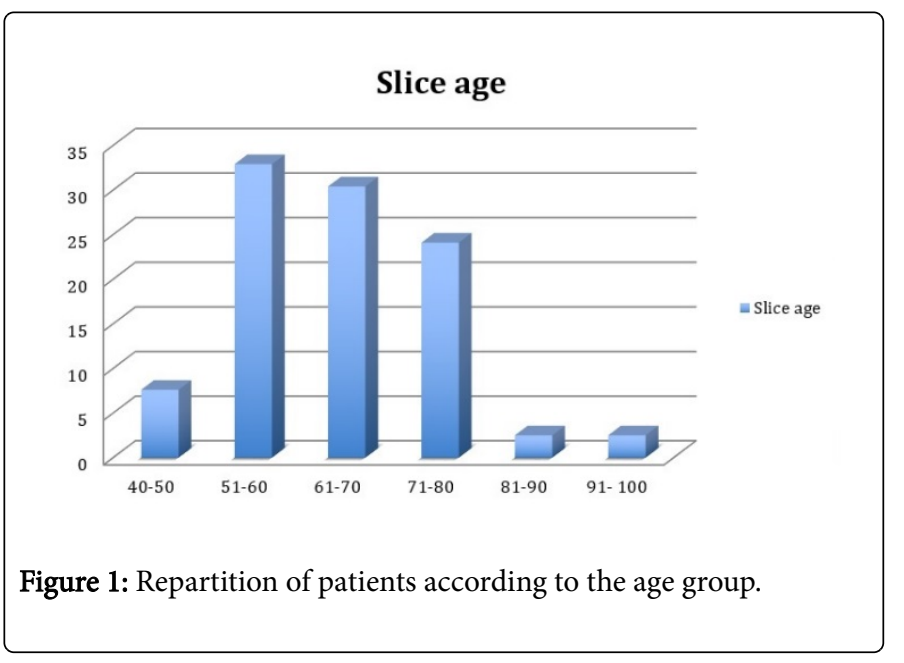

Neurol Disord, an open access journal

\begin{tabular}{|l|l|l|}
\hline TOAST & Frequencies & Percentage \\
\hline Atherosclerosis & 23 & $37.1 \%$ \\
\hline Arteriolosclerosis & 35 & $56.5 \%$ \\
\hline Embolic cardiopathy & 4 & $6.4 \%$ \\
\hline Other origin & 0 & $0.0 \%$ \\
\hline Unknown origin & 0 & $0.0 \%$ \\
\hline Total & 62 & $100 \%$ \\
\hline
\end{tabular}

Table 1: Ischemic stroke etiology according to the TOAST classification.

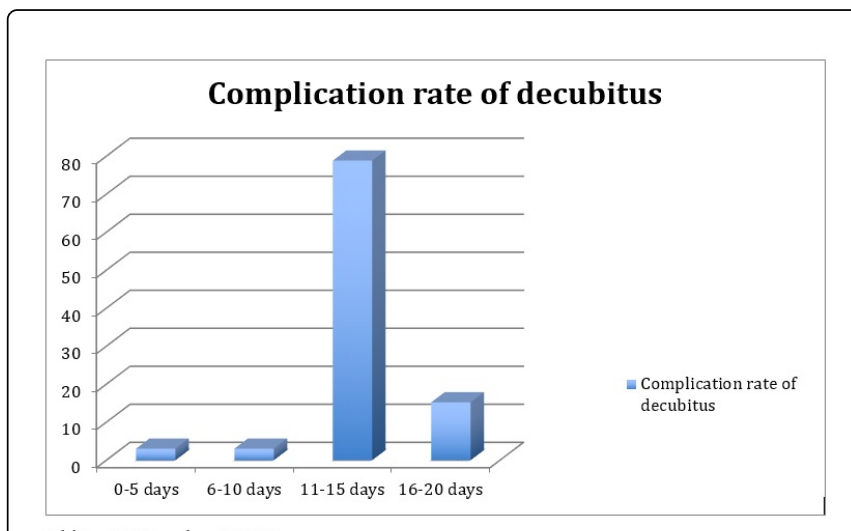

Chi2 $=10,75$ and $\mathrm{p}<0,005$

Figure 2: Length of days and up come of decubitus complications.

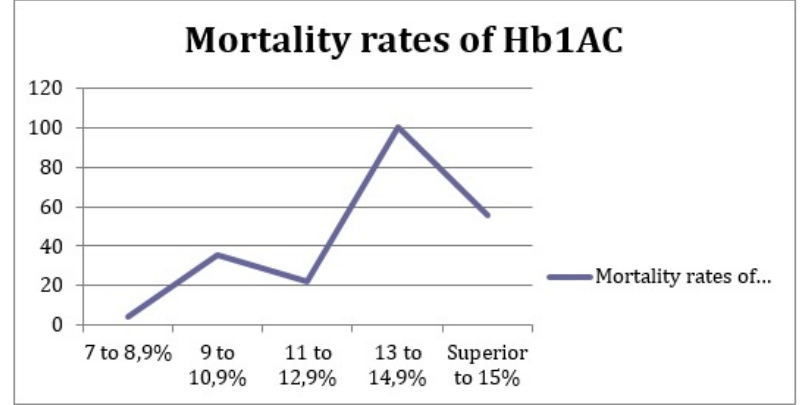

Khi2 at 12,417 and $\mathrm{p}<0,02$

Figure 3: Correlation between the elevation of HB1AC rate and the mortality.

\section{References}

1. Stamler J, Vaccaro O, Neaton JD, Wentworth D (1993) Diabetes, other risk factors, and 12-year cardiovascular mortality for men screened in the multiple risk factor intervention trial. Diabetes Care 16: 434-444.

2. Selvin E, Coresh J, Shahar E, Zhang L, Steffes M, et al. (2005) Glycaemia (haemoglobin A1c) and incident ischaemic stroke: The Atherosclerosis Risk in Communities (ARIC) Study. Lancet Neurol 4: 821-826.

3. Aka-Anghui Diarra E, Zakaria M, Mourtada WD, Kouassi KL, Yapo Ehounoud C (2015) Current data on the profile of patients hospitalized 
Citation: Mamadou Z, Kouamé AA, Tanoh C, Boubacar S, Gueumekane EBL, et al. (2016) Stroke of Diabetic Subject: Experience of The Neurology Service of Cocody Teaching Hospital at Abidjan (Ivory Coast). J Neurol Disord 4: 304. doi:10.4172/2329-6895.1000304

Page 4 of 4

for stroke in a neurology department in West Africa: Abidjan (Ivory Coast). American Journal of Psychiatry and Neuroscience 3: 14-21.

4. Tuomilehto J, Rastenyte D, Jousilahti P, Sarti C, Vartiainen E (1996) Diabetes mellitus as a risk factor for death from stroke. Prospective study of the middle-aged Finnish population. Stroke 27: 210-215.

5. Burchfiel CM, Curb JD, Rodriguez BL, Abbott RD, Chiu D, et al. (1994) Glucose intolerance and 22-year stroke incidence. The Honolulu Heart Program. Stroke 25: 951-957.

6. Diabetes in the Africa region: 2012 update for IDF.

7. Laakso M, Lehto S (1998) Epidemiology of risk factors for cardiovascular disease in diabetes and impaired glucose tolerance. Atherosclerosis 137 Suppl: S65-73.

8. Haffner SM, Lehto S, Rönnemaa T, Pyörälä K, Laakso M (1998) Mortality from coronary heart disease in subjects with type 2 diabetes and in nondiabetic subjects with and without prior myocardial infarction. N Engl J Med 339: 229-234.

9. Benatru I, Rouaud O, Durier J, Contegal F, Couvreur G, et al. (2006) Stable stroke incidence rates but improved case-fatality in Dijon, France from 1985 to 2004. Stroke 37: 1674-1679.

10. Anderson CS, Carter KN, Hackett ML, Feigin V, Barber PA, et al. (2005) Trends in stroke incidence in Auckland, New Zealand, during 1981 to 2003. Stroke 36: 2087-2093.

11. Gray CS, Scott JF, French JM, Alberti KG, O'Connell JE (2004) Prevalence and prediction of unrecognised diabetes mellitus and impaired glucose tolerance following acute stroke. Age Ageing 33: 71-77.

12. Almdal T, Scharling H, Jensen JS, Vestergaard H (2004) The independent effect of type 2 diabetes mellitus on ischemic heart disease, stroke and death: A population-based study of 13,000 men and women with 20 years of follow-up. Arch Intern Med 164: 1422-1426.

13. Hart CL, Hole DJ, Smith GD (2000) Comparison of risk factors for stroke incidence and stroke mortality in 20 years of follow-up in men and women in the Renfrew/Paisley Study in Scotland. Stroke 31: 1893-1896.
14. [No authors listed] (1998) Tight blood pressure control and risk of macrovascular and microvascular complications in type 2 diabetes: UKPDS 38. UK Prospective Diabetes Study Group. BMJ 317: 703-713.

15. Béjot Y, Giroud M (2010) Stroke in diabetic patients. Diabetes Metab 36 Suppl 3: S84-87.

16. Caplan LR (2015) Lacunar infarction and small vessel disease: pathology and pathophysiology. J Stroke 17: 2-6.

17. You R, McNeil JJ, O'Malley HM, Davis SM, Donnan GA (1995) Risk factors for lacunar infarction syndromes. Neurology 45: 1483-1487.

18. Grau AJ, Weimar C, Buggle F, Heinrich A, Goertler M, et al. (2001) Risk factors, outcome, and treatment in subtypes of ischemic stroke: the German stroke data bank. Stroke 32: 2559-2566.

19. Lodder J, Bamford JM, Sandercock PA, Jones LN, Warlow CP (1990) Are hypertension or cardiac embolism likely causes of lacunar infarction? Stroke 21: 375-381.

20. Petty GW, Brown RD Jr, Whisnant JP, Sicks JD, O'Fallon WM, et al. (1999) Ischemic stroke subtypes: a population-based study of incidence and risk factors. Stroke 30: 2513-2516.

21. Stevens RJ, Coleman RL, Adler AI, Stratton IM, Matthews DR, et al. (2004) Risk factors for myocardial infarction case fatality and stroke case fatality in type 2 diabetes: UKPDS 66. Diabetes Care 27: 201-207.

22. Labovitz DL, Boden-Albala B, Hauser WA, Sacco RL (2007) Lacunar infarct or deep intracerebral hemorrhage: who gets which? The Northern Manhattan Study. Neurology 68: 606-608.

23. Inzucchi SE, Bergenstal RM, Buse JB, Diamant M, Ferrannini E, et al. (2015) Management of hyperglycemia in type 2 diabetes, 2015: A patientcentered approach: Update to a position statement of the American Diabetes Association and the European Association for the Study of Diabetes. Diabetes Care 38: 140-149. 